\title{
Unequal choosing
}

\section{Introduction}

The I980 Education Act, introduced under Margaret Thatcher, included the requirement for local education authorities (LEAs) to consider parental preference more seriously. The notion of parental choice had been established under section 76 of the 1944 Education Act but had been implemented only on an ad hoc basis (Croft 2004). Commitment to parental preference was strengthened in legislation in I988 and I989, with the introduction of the principle of funding following the pupil introduced in I988. For Gunter and McGinty, the Education Reform Act of I988 established the 'independent' school as the ideal model, achieved through 'removing the school from local democratic accountability by building on the self-managing school as a business in a competitive market place' (Gunter and McGinty 20I4: 300-I). This further enshrined the concept of 'choice' in schooling. ${ }^{1}$ Choice, diversity and the market model of schooling have continued to shape policies around academies and free schools. This has also been driven by the desire to take schools out of local authority control on the assumption that schools are better if parents and other actors - for example, those engaged in business, religious groups or universities - play an active role in them. In fact, as the range of social actors brought into the educational sphere widened in the 20IOs, it could be argued that the primacy of the parent as active citizen as well as consumer has slightly reduced. It was the I980 Educational Act that confirmed the statutory right of parents to be elected as school governors, giving them an important role in the governing of schools as the control of schools was increasingly shifted from Local Authorities (LAs) to governing bodies. However, in May 2016 the then Education Secretary, Nicky Morgan, suggested that, in a bid to get the best people with the right skills on governing bodies, there 


\section{All in the mix}

should no longer be the requirement to have at least two parents on governing bodies. ${ }^{2}$

Nonetheless, despite these changes, the primacy of parental choice in schooling as a discourse and policy objective remains. Parental choice has also been a key justification used for arguments around diversification of provision. A variety of schools are seen as offering more choice (despite, as we shall see below, the geographical limitations within which choices are made) (Wilkins 20I0: I74). Over the last ten years, the logic of variety of provision has extended to the introduction of free schools and the shift in the policy around academies (West and Bailey 20I3, Simkins 20I4). Free schools were introduced in 20II with the idea that parents could also create their own state-funded schools if they are unhappy enough with the available choices. In this development, parents as active citizens can, if they have the will and organisational capacity, potentially cross the divide from consumer to consumer-producer. Yet at the same time, it is important to remember that, despite often functioning as a lodestone for political debates on education, free schools make up a very small proportion of the overall school provision, with parentled free schools a minority of those which have had governmental support. ${ }^{3}$ In an as-yet more far-reaching policy, successive governments have increasingly incentivised schools to convert to being academies. Academies, known as "publicly funded independent schools', are funded directly by central government and thus are outside the control of local authorities (Academies Commission 2013: 5). Academisation was initially developed under the Labour government in 2002 and was largely used as a way of dealing with 'failed' schools which were taken away from LA control. Academies were given freedoms that were not available to LA-maintained schools. These included freedoms such as establishing their own pay and conditions for staff; some flexibility in curriculum provision; flexibility in the composition of the governing bodies and freedom over the length of the school day; and number of sessions taught (Long 20I5). Importantly, academies also have more control of admission procedures and exclusion which add another potential layer of selection. The failing school in a disadvantaged area continues to be a potential route to academisation. However, under the successive Coalition and Conservative governments, the possibility of conversion to an academy has now also become a choice offered to successful schools (Gunter 20I2, Gunter and McGinty 20I4, Courtney 20I5: 


\section{Unequal choosing}

802). As a result, there has been a very rapid growth in the number of academies. In May 2010, there were 203 academies in the UK and by November 2012 this had risen to 2456 and then risen again to 6087 by March 2017 (making up 22 per cent of primary schools and 62 per cent of secondary schools). ${ }^{4}$ By 2016 it was declared a government ambition for all schools to become academies (although as yet this policy has not been realised). ${ }^{5}$ The impact of the process of academisation on inequalities in education has yet to be fully studied. Certainly, the effect of free schools and academies on the quality of schools has been unimpressive (Pickett and Vanderbloemen 20I5: 20). However, Stephen Gorard points out that, whilst the first type of academisation (of failing schools) tended to reduce the clustering of poorer children in specific schools, the more recent focus on successful schools becoming academies ignores any concerns for social justice and is likely to increase the incidence of local segregation by socio-economic status (Gorard 2014: 296).

Thus, through a series of structural changes over the last three and a half decades, the relations between the state (in its form of local or central government) and schools and parents have been transformed towards the construction of parents (and occasionally young people) as consumers of educational options for their children. This marks a shift in education discourses away from concerns around inequalities, exclusion or general social welfare towards the 'parentocracy' made up of individual consumers (Reay et al. 20II). This is significant not just for its impact on classed or ethnic inequalities, it also has significant implications in terms of disability. Stephen M. Rayner (20I7) has discussed the impact of the regulated, competitive market on school leaders' ability to respond to the needs of children with special educational needs (SEN) and disabilities. Ball (2003: 49) also notes how SEN programmes were dismantled or de-emphasised at the same time as able student programmes were introduced. In addition, academies tend nationally to have higher levels of permanent exclusions (Long 2015: I0). For Stambach and David, the introduction of the parentocracy also shifts parenting towards a masculine mode as education becomes about competition rather than nurturing (Stambach and David 2005, see also David 1997). As will be discussed in Chapter 3, the act of choosing itself can also be gendered within the household, although in sometimes complicated ways (David I997). Somewhat paradoxically, at the same time as individual parental choices have been emphasised and some schools given more 


\section{All in the mix}

freedoms, what is taught in the majority of state schools has come under increasingly centralised control with the development of - and ongoing adjustments to - the national curriculum. ${ }^{6}$

Politicians and policy-makers tend to claim that parents have been empowered through their new role as consumers of educational options for their children. In 2005 the Labour government, which continued the promotion of market principles in education, produced the white paper Higher Standards, Better Schools for All: More Choice for Parents and Pupils. Its stated aims were to 'radically improve the system by putting parents and the needs of their children at the heart of our school system' (quoted in Reay et al. 20II). Yet the market, as represented by parent choice, may not be a sufficient push for poorerachieving schools to improve standards (Allen et al. 20I4). The operation of education as a market does not necessarily achieve a reduction in social inequalities, as Lupton argues: 'It is reasonable to assume that the more choice, the more unequal the opportunities' (Lupton and Thomson 2015). As we shall see in the following sections, there are concerns about the ability of parents to achieve the same educational opportunities for their children. Is the increased choice equally spread?

Having briefly considered the policy landscape of school choice, this chapter will consider the impact of this expansion of choice on questions of inequality. In particular, it will elaborate how classed and racialised inequalities are maintained through operations of choice. In order to track the classed nature of choosing, the chapter will draw on Bourdieusian theories of class which have been particularly influential in the field of education. However, the chapter will also argue that Bourdieusian understandings of class, as they are often used in the literature on school choice, risk overlooking the importance of racialised understandings of self and identity which may also play a role in shaping school choice. The chapter will track how the current literature on school choice has overlooked questions of race and frequently also ignored the experiences of working-class parents, whether white or of ethnic minorities. Finally, the chapter will explore how the spatial nature of school choice has also been frequently overlooked. It will argue that narrations of place - and spatial tactics and strategies - are key to understanding how schools' reputations are embedded in their geographies. 


\section{Unequal choosing}

\section{Choice, class and ethnicity}

The opportunity to choose their children's schools and have more say in their schooling may be welcomed by some. Yet it can also be perceived as a burden for parents as they negotiate a complex educational system governed by a proliferation of different types of schools with different rules of access. Choosing schools is made more complex through this variation. Courtney has attempted to map the variation in school types in England and has concluded that:

if one includes variations according to pupil sex and age which have largely been omitted from these typologies for simplicity, there are presently between 70 and 90 different types of school in England. This is not to say that parents may choose from this number: a significant proportion selects the pupil, albeit covertly and/or through branding. (Courtney 20I5: 8I4)

Despite this variation, and although there is no simple or uniform schema for admission to schools, distance from residence to school remains an important factor in admissions. This has particular implications for the relationship between schools, inequalities and place, as will be discussed below. LAs, academies and free schools have relative freedom to formulate their own mechanisms of prioritising pupils (within certain bounds established by the 2003 Code of Practice on School Admissions (Croft 2004: 930)). Possibilities of choice are also shaped by the various types of (wholly or partially) selective schools - including grammar schools; religious schools and other voluntary aided schools; academies; technical colleges; and specialist schools. In addition, there is a complicated system of appeals which parents may have to negotiate if they are unhappy with the school their child has been allocated to (Croft 2004). Thus, skills and knowledge are required to navigate the complex terrain of different schools and admissions procedures. As much of this knowledge is acquired through 'hot' sources of personal networks (which will be discussed further below), this can lead to disadvantage for those who, for a range of different reasons, have less extensive or effective local networks.

As suggested above, the dominance of models which have at least some element of proximity of residence to school as a criterion means that parents and children have limits on choice set by their geographical locations. Although those with the economic power to move 


\section{All in the mix}

may be able to move into the catchment areas of particular schools, even for those with the financial resources this is limited by the uneven distribution of different types of schools. Realistically, many families cannot afford to move and those who can are still likely to be tied to particular broad areas and regions by employment and other attachments. Importantly, in discussions of school choice, it is often forgotten that exercising choice tends to be most possible in urban, city areas. In rural areas or small towns, particularly at secondary school level, there may be almost no choice (Reay et al. 20II). The 'market' of schooling therefore has profound geographical rigidities and significant barriers to full engagement. The difficulty of navigating the process of choosing schools was recognised with the introduction of Choice Advisor Services based in Local Authorities in the 2006 Education Act (Exley 20I2). Choice advisers were established to provide a service for the 'disadvantaged' and 'vulnerable'. The establishment of these services risks implying that it is the parents' choosing which may be at fault, rather than any inadequacy in the choices available to them. In her study of LA advisers, Exley (20I2: 8I) found that many saw themselves as "helping working class and disadvantaged parents "make the best of a bad situation"' rather than actually facilitating positive choices.

Whilst choices may be extremely limited in rural areas, even within urban areas, as we shall see in Chapter 3, parents often feel a lack of choice. The education market is affected by limits of supply (schools cannot easily 'spring up' to meet a demand) which means that schools do not operate in a pure market. The cost of some schools being winners in the market for students and funding is that others will be losers. Yet many children still have to attend those 'losing' schools. There are only so many places which popular schools can offer for students and, for many parents and children, the notion of choice becomes a fiction, particularly in those areas where all the possible choices are considered unpopular or undesirable. Thus, as the discourse around schooling has shifted to one of individual parents' choices, the question is raised as to whose choices are increased, and what impact does the notion of choice have on well-established inequalities in education provision and outcomes. For Reay et al (Reay et al. 20II: 68), 'the powerful idea that successful secondary schooling is the result of parents making "good" choices at the point of transition is itself something that conceals the maintenance of inequalities'. The next two sections will consider in more detail how 


\section{Unequal choosing}

classed and racialised inequalities are maintained through the operations of choice. It will also explore how these questions have been addressed in the literature concerned with the sociology of education and of class and race.

\section{Researching class and race in education}

As Andrew Sayer (2005) points out, it is unusual for anyone other than a sociologist to ask you what class you are - because it is considered rude, or obvious. However, at the same time, the sociologist who dares to ask might well not agree with your self-identification - there are many forces going on behind people assigning themselves (or others) a class which may not match up to a schema or concept of class that the sociologist might agree with. Indeed your non-sociologist neighbour might also not agree with your self-identification as there are conflicting lay understandings of class and its markers. Sayer (2005: I) suggests that class talk is emotional and evaluative: '[c]ondescension, deference, shame, guilt, envy, resentment, arrogance, contempt, fear and mistrust, or simply mutual incomprehension and avoidance, typify relations between people of different classes'. However, this list may be unduly negative and ignores some everyday processes of cross-class conviviality which Gilroy (2004) has argued that we need to pay attention to in racialised relations. Nonetheless, explicit examination (in contrast to coded and implicit references) of class is often left to academic rather than everyday discourse.

Amongst sociologists, the study of education is one site where the rise and fall (and rise again) of class theory within sociology has been played out. There are two distinct questions in this ambivalence of the utility or relevance of class within the sociological literature. One is largely focused on identity: can it be possible to talk about class if many declare either that class is irrelevant to them, or if, in the everyday usage, people put themselves in categories which a sociologist might want to disagree with (Are we all middle class - taken to mean 'ordinary' - now? Has class become irrelevant?). Yet at the same time as this question is asked, it is clear that significant social and economic inequalities remain and are reproduced across generations (Bottero 2005). More recent forms of class analysis have argued that there does not need to be a recognisable class consciousness for classed processes to exist. Indeed dis-identification, which involves 


\section{All in the mix}

the denial of a classed identity, may be seen as a classed practice, as working-class is often seen as spoiled identity which should be resisted or disavowed (Skeggs I997, Reay I998, Bottero 2009). In addition, there has been opposition to the singular focus on economic relations as the sole force structuring inequalities and class. In response, there have been more culturally inflected approaches to class which explore how class inequalities are bound up in a range of practices which range from what we eat, how we speak, how we dress, to how we move our bodies and how we spend our leisure time. This raises the possibility of identifying social classes 'who share common lifestyles, identities, social networks and political orientations as well as levels of income and wealth' (Savage 2015:3). ${ }^{7}$

The second dilemma about class as a category of analysis emerges out of the first and centres on questions of categorisation or the counting of class. Traditionally, sociologists have tended to categorise people by their occupation (or often by their father's or husband's occupation), with individual jobs located a place in a hierarchal schema of occupational groups. However, it is increasingly recognised that modern patterns of work and career building do not fit easily into these rigid schema. This is a feature of the changing nature of employment - for instance with the decline of employment in craft or heavy industries and the growth in more insecure employment in a range of occupations. In addition, it has become clear that a focus purely on employment and occupational categories fails to describe the experiences of class as it is built out of more than occupation. Indeed, Mike Savage argues that occupational schemas of class classification were never purely economic but also cultural - intended as 'ways of making cultural judgements about ranking and social importance of jobs' (Savage 2015: 35).

For those taking a broader position on the importance of culture in how class plays out, the dominant approach is that outlined by Pierre Bourdieu. For Bourdieu, the operation of class in society does not require the identification of cohesive or self-identifying groups or class formations. For Bourdieu (I99I), a class is a set of people in a similar position in the 'field' who have shared dispositions and interests which make them act in particular ways (but not necessarily in a co-ordinated way, and not as a group). This produces a concept of classed groups without distinct boundaries, where contesting the boundary itself is in fact a key class practice. For those enacting them, the shared tastes and practices may seem personal and relatively 


\section{Unequal choosing}

arbitrary. However, these dispositions are patterned and produced relationally where they gain social meaning through processes of social interaction, which are already shaped by social hierarchies and differential association. Attention to the patterning of those shared 'dispositions' and the distinctions that they make between social groups alerts us to the importance of understanding how the values given to different social and cultural capitals develop. For Bourdieu, class is hierarchical relationship between social groups which are shaped through ways of being, tastes and lifestyles. According to Swartz, Bourdieu is interested in 'the question of how stratified social systems of hierarchy and domination persist and reproduce from one generation to the next without powerful resistance and without the conscious recognition of their members' (Swartz I997: 6). Thus, education is critical in understanding class and the reproduction of hierarchies and inequalities.

There is a paradox in the fact that education is often considered an important mechanism of social mobility and meritocracy, yet success in education is strongly facilitated by cultural capital and thus the maintenance of class distinctions. As families cannot simply secure the right jobs and futures for their children, education is the means to ensure the maintenance of social privilege, not only through the acquisition of qualifications but also through the transmission of class codes and cultural capital. "The "eye" is a product of history reproduced in education' (Bourdieu I994: 5-6). This 'culturalist' approach to class, which seeks to understand classed practices rather than self-conscious class identities, has been very productive in aiding the analysis of the reproduction of class inequalities in education. Thus for Stephen Ball:

Class is realised and struggled over in the daily lives of families and institutions, consumption decisions, as much as in the processes of production and particularly at moments of crisis and contradiction as parents think about the well-being and happiness and futures of their offspring. Class is about knowing how to act at these defining moments. (Ball 2003: 7)

This approach emphasises the way in which class is lived and understood relationally - manifested in common ways of being, tastes and practices - but class here is not necessarily self-conscious or collective (Bottero 2005). Thus attention is given to relations between people who occupy similar positions within a field - as well as between 


\section{All in the mix}

those who have different social positions which people may want to distinguish themselves from. Who you are not, the tastes you would never display, are as important here as who you are and your tastes and dispositions. ${ }^{8}$ Class positions are maintained through relations and interactions with the 'right' people and the exclusionary practice of distinction as well as the accumulation and transmission of economic, social and cultural capitals from one generation to the next. It can also be maintained by processes of self-exclusion, where activities and spaces are seen as not being 'for the likes of us' or where the risks (to comfort, to a stable sense of self as well as to economic well-being) of engagement can appear to be too high (Bottero 2005).

For Bourdieu, cultural capital can be embodied as a disposition of the mind or body, it can be in concrete cultural goods and it can be institutionalised in the form of qualifications. Education is key in the acquisition of qualifications, although the worth of certificates and degrees may over time become devalued in a period of increasing access to higher education. This leads to a pressure to acquire more advanced degrees (Bourdieu 1994: 133). Yet beyond qualification acquisition, education is also important in the acquisition of taste and the right dispositions which play a critical role in creating cultural capital through distinction (Bourdieu 1994). This makes schools very important in the conscious or unconscious struggle to maintain position. Schooling transfers social capital through promoting social networks which may be important in the parents' lives and will certainly be important for the children (Byrne 2006a). Who your children make friends with and spend their time with shapes this social capital and gives them the social skills to continue to accrue the right social and cultural capital in the future. Education and schooling also provide cultural capital, being one site where children develop tastes and dispositions and where they learn how to act and be comfortable in particular social settings. Cultural and social capital ensure that individuals can feel at ease within a habitus (or in fact several potentially overlapping habitus). For Bourdieu, habitus is a system of embodied dispositions which are produced relationally and which structure the social world - ranging from 'hexis' (ways of using one's body, speaking etc.) to schemes of perception and classification which shape how we perceive and interact with the social world. For Reay et al. (20II), habitus is a set of 'durable transposable dispositions' which emerge out of histories of experience - of individuals, families and social groups. ${ }^{9}$ Those who are at ease at operating within a certain 


\section{Unequal choosing}

habitus will have a superior 'feel for the game' and thus are more likely to thrive. They will also tend to act in ways which reproduce that habitus, thus maintaining the advantages of those in a similar position in the social field. Those who, through social mobility for example, move into fields that they are unfamiliar with may have 'fish out of water' experiences, where they lack the right habitus to feel comfortable and to operate successfully within the field. As we shall argue below, much of the work inspired by this notion of habitus ignores its racialised nature. The experience of being a 'fish out of water' can also be racialised as individuals may experience the impossibility of truly fitting in due to racialised othering. Thus, in predominately white spaces, black and Asian pupils may experience themselves as 'space invaders' (Puwar 2004).

The framework of understanding the relationships between structure, dispositions and practice which Bourdieu offers, whilst invaluable in many ways for educational research, has not often been used in ways which reflect the complexity of social location in education, in particular in terms of race, ethnicity and gender (for exceptions see Smaje I997, Hancock 2005, Reay 2008, Reay et al. 20II). As Archer and Francis suggest: 'theories of social class have been primarily formulated with reference to White communities, and hence care must be taken when extending these notions to minority ethnic communities' (Archer and Francis 2007). In addition, those uses fail to understand the importance of analysing the experience of white communities as white (Byrne 2006b, 2009). Whilst much of Bourdieu's work lacks attention to questions of race and ethnicity, he does allow for other forms of distinction to be operating in the field, such as gender and race (Wallace 20I6). ${ }^{10}$ In considering gender in particular Andrew Sayer argues that '[i]n Bourdieu's analysis, the logic of class and status is given the dominant, contextualising role, with gender as a modifier' (Sayer 2005: 82). The consigning of gender or race to the status of a 'modifier' risks re-inscribing a primacy to the economic, which Bourdieu sought to overcome. Even with a more balanced view on the interactions between class, gender and ethnicity, awareness of the field as both racialised and gendered as well as classed can be difficult to operationalise in practice. ${ }^{11}$ Bourdieu himself does not provide a model for how to achieve this more complex understanding. As Terry Lovell (2000: 36) argues, Bourdieu's sociology is in danger of positioning sex/gender, sexuality and even 'race' as secondary to social class: '[w]hile class penetrates right through his 


\section{All in the mix}

[Bourdieu's] diagrammatic representation of the social field, like the lettering in Brighton rock, gender is largely invisible, as is race'. If we are to understand the multiple interrelations between race, class and gender, then it is possible that Bourdieu's construction of habitus does not offer sufficiently flexible analysis to reach the complex processes behind identification. Archer and Francis (2007) for example, in their exploration of minority ethnic achievement in schools, argue for a multi-layered theoretical framework. As well as using Bourdieu's work, they also draw on post-structuralist theorisations of identification offered by both Stuart Hall and Judith Butler: '[w]ithin this approach, social identities, divisions and inequalities (of race/ ethnicity, social class, gender and sexuality) are understood as being brought into being through social life - through talk, actions, policies, practices and so on' (Archer and Francis 2007: 25-6). This discursive, performative approach relies on a more diffuse notion of power and the performance and embodiment of identities than is usually associated with Bourdieu.

When considering race, everyday discussions of race and ethnicity can be equally contentious as those surrounding class. Race and ethnicity can be conceptually distinguished from each other - with race taken to mean groups identified by their sharing a set of biological largely visible somatic features and ethnicity to be a more culturally inflected notion of human groupings. However, in practice, we would argue that both terms are often used in such overlapping ways (where members of ethnic groups are considered to have some biological 'in the blood' relationship to each other and racial groups are seen as sharing cultural characteristics) that they are often used indistinguishably. Frequently, the terms ethnicity or ethnic group are used to suggest a progressive move away from race when in fact a logic of biological race is still being called upon. These conceptual muddy waters raise problems for scholarly research. Ideas of race (and by extension many renderings of ethnicity) that rest on notions of biology have been conclusively repudiated. There is a scholarly consensus that race has no biological basis - it is not a 'natural' or inevitable way of categorising or regarding human beings and visible physical differences between humans do not have a link to physical or intellectual abilities or character traits (Jones I996). However, this still raises the question of the on-going impact of ideas of race on people's lives and ways of thinking about themselves and others. The enduring power of race as a way of dividing people means that it continues to have effects: 


\section{Unequal choosing}

'although we might say there is no such thing as race as the intrinsic property of bodies, this does not mean that race does not exist as an effect of the very way in which we think, know and inhabit the world' (Ahmed 2002: 47). Drawing on the work of Judith Butler, Byrne has argued elsewhere (Byrne 2006b; 20II) that race needs to be understood as an embodied performative. That is, that the repeated citation of racialised discourses and the repetition of racialised perceptual practices produce the idea of differences, rather than being an effect of them. These socially constructed differences then, through mechanisms of individual and structural racism and racialisation, have an impact on people's everyday lives and life chances.

The fate of different racialised groups within the UK educational system has been given some attention ever since comparatively larger numbers of racialised minority groups entered the education system following the Second World War. Initially, this research focused on essentially conservative issues around how schools might be a site for easing the tensions understood to result from mass immigration of racialised groups - or how they might promote assimilation (Rattansi I992). This researched has included work on the 'underachievement' of racialised groups (Gillborn 2006, Burgess and Greaves 2013) as well as a focus on in-school relationships between children and between teachers and children. There has been a concern in this work on race to consider how racism is present in schools. This has included attention to teacher-child and child-child relations and bullying and lowered expectations by teachers of ethnic-minority children (Hewitt I986, Troyna and Hatcher I992). Scholars have also considered how schools might be sites of education in multi-culturalism and antiracism (Rattansi I992, Yuval-Davis I992, Bonnett 2000). Recently, research has become more attuned to the complexities of understanding minority ethnic experience in British schools. In particular, there is more awareness of the need to differentiate between ethnic groups, and to track how trajectories of arrival, settlement and placement in the system and processes of racialisation produce different outcomes (see for example Archer and Francis 2007). There has also been some interesting work on questions of race, ethnicity and gender. This includes work on racialised masculinities and the ways in which gender and sexuality interact with race in producing different learning cultures and opportunities (see Mac an Ghaill 1996, Archer 2003).

This section has outlined the approach to class and race to be used in this book and the next will focus specifically on the literature 


\section{All in the mix}

concerned with school choice, arguing that there has been a tendency (with some exceptions) for this literature to focus on the experiences of white middle-class parents without reflection on the ways in which their experiences and positions are racialised.

\section{Research on school choice: gaps in the literature}

As mentioned above, the focus on class and the reproduction of inequalities has a long history within the sociology of education (see Ball 2008 for a review) and mirrors in many ways broader shifts and concerns about class in wider sociology. Within the current focus on education and class, there is a desire to track how class - or socioeconomic status - inequalities fare as the education system is moved towards logic of the market rather than social welfare. In addition, education, and the composition of school intake, have been seen as an area of key concern in the 'genteel battles' (or perhaps not so genteel battles) the middle class are engaged in to assert and maintain their positions (Savage et al. I992: I00). As Bev Skeggs argues: 'choice is a particularly middle-class way of operating in the world' (Skeggs 2004: I39). For Reay et al., 'the educational system has become a central mechanism of white middle-class identity formation' (Reay et al. 20II: I9). Of course, with the existence of a private sector of education, as well as selection by geographical area, choice has always been available to those with the financial means to exercise it. Yet there is an argument that, as choice plays a potentially larger role in the state education system, this has the potential to further embed class (and racialised) inequalities. One area of focus has been the clustering of pupils with similar socio-economic status (largely measured through the numbers of children receiving free school meals $(\mathrm{FSM}))^{12}$ in schools and the impact this has on pupils' and wider social outcomes (Gorard 20I2). Schools are more segregated than neighbourhoods in almost all parts of England (Burgess et al. 2007). Burgess et al. have found that:

The interplay of the decisions of schools, parents and LEAs produces an outcome in which there is clustering together of pupils scoring well in the Key stage tests, and a clustering together of pupils from poorer backgrounds. This is unlikely to be to the advantage of the latter pupils. (Burgess et al. 2006: I4)

They found that clustering of pupils according to socio-economic background was higher where there was more choice. But they also 


\section{Unequal choosing}

found that sorting was lower in LEAs with comprehensive schools, even where there was choice. Burgess and Briggs (2006) have shown how pupils eligible for FSM attend lower-performing schools than those not eligible for FSM living on the same streets, suggesting that spatial dynamics and housing price alone cannot explain the difference. Nonetheless, as Allen et al. (20I4) demonstrate, empirical observations which show differences of school choice outcomes cannot explain the nature of the relationship between school choice and social class. Qualitative research, which is able to explore parental perceptions, is better placed to open up at least the parental side of the choice equation in ways which can illuminate some of the classed and racialised practices in choosing schools as well as the effect of different processes which enable some parents to achieve their most desired outcome.

One possible explanation suggested by both quantitative and qualitative research is that choice is a mechanism through which the middle classes can and do seek each other out, or seek to avoid undesirable others. It is interesting that there has been much less consideration of the possibility that some working-class parents might be equally seeking each other out - perhaps in the desire to find schools where their children will fit in and be comfortable. In the case of middle-class parents, it is argued that, for this group, the demographic make-up of individual schools is considered particularly important because much of the learning and socialisation which the middle classes most care about is to be done from interactions with fellow pupils as much as with teachers. Not all of the middle-class focus on education is concentrated in school choice, of course. Much of what middle-class parents do in the educational field may be outside of the context of schools, in extra-curricular practices such as music and sports and in everyday ways of being in a family and modes of interaction and conversation: the 'concerted cultivation' that Lareau describes in the USA (Lareau 2002). Nonetheless, in a context where choice amplifies the importance of parental action, there has been intense focus in the literature on the extent to which the middle classes may be 'working the system' - or, as Bourdieu described it, having a better 'sense de jeu' (sense of the game). For Stephen Ball,

choice policies, or post-welfare education policies, offer a social and political context, and produce social fields or social spaces, in which the middle class feel both at home and at risk, comfortable but uncertain. (Ball 2003: I67) 


\section{All in the mix}

Ball highlights the tensions implicit in having choice. Choice may seem like a good thing - especially if a sense of having discernment and good judgement is an integral way of your being in the world. Yet at the same time, choice introduces uncertainties and the feeling of the possibility of missing possible options, or making the wrong choices. It also raises the possibility for feelings of rejection and disappointment for children at an important and difficult point in their lives, in the transition to secondary school. In addition, as Sayer argues, 'for the middle classes, parenting has itself become deeply competitive' (Sayer 2005: I29).

It is a common thread in the literature on school choice and the middle classes to explore the desire to find a school filled with enough 'people like us' who will teach children 'how to be'. ${ }^{13}$ In a previous article, Byrne (2009) critiqued much of the literature on school choice for the way in which it failed to account for respondents' racialised positions - often by simply failing to explicitly report respondents' racialised position, particularly when they were white (Ball 2003, Croft 2004, Devine 2004, Bruegel 2006 and Raveaud and van Zanten 2007). ${ }^{14}$ Thus there was no analysis of how the accounts of white middle-class respondents, in particular, reflected concerns about racialised difference as well as class difference. More strikingly, the quotations from the respondents in this body of research often revealed their thinking about issues surrounding race and ethnicity and school choice, but these parts of their accounts were not commented on or analysed. In addition, the concerns of both workingclass and ethnic-minority parents have been somewhat overlooked in the literature on education and choice with its focus on white middle-class experience (see for example Benson 20I4, Perrier 20I2, Cucchiara and Horvat 20I4, Ball 2003, Ball and Vincent 2007, Devine 2004, Jackson and Bisset 2005, Power et al. 2003, Raveaud and van Zanten 2007, Reay et al. 20II, Snee and Devine 20I4). While this literature makes much of the desire for sufficient 'people like us' to give the middle classes a sense of safety and community, it largely fails to explore not only how this is experienced by working-class parents but also how this might be a racialised as much as a classed desire. There is a risk that, by focusing on 'middle-class' anxieties, practices and strategies around school choice, the assumption builds that somehow only those positioned as middle class (and often assumed to be white) are concerned to exercise choice and worried about how they exercise it. If we consider questions of belonging (May 20I6), then the desire 


\section{Unequal choosing}

to be with 'people like us' might be similar for those positioned as working-class and those from racialised minorities, who also don't want their children to suffer from snobbery or racism - or to have a 'fish out of water' experience (see also Reay and Ball I998).

In a study of primary school choice, Burgess et al. (20I5) found that the choices of parents from lower socio-economic-status groups were more associated with a preference for schools with larger proportion of FSM-eligible pupils, in contrast to parents with higher socio-economic status who were less likely to apply to those schools. Feelings of recognition and a sense of belonging may lie behind these differences. In addition, for ethnic minorities, the extent to which 'people like us' is racialised as much as classed may have a particular urgency in the wish to avoid experiences of racism (Ball, et al. 20II). Debbie Weekes-Bernard (2007) found that some Black and Asian parents faced a complex negotiation between wanting their children to be in a comfortable situation where they would not face racism, and at the same time wanting to avoid schools stigmatised for having too many ethnic minorities. The preference for more local schools may be the outcome of a combination of financial constraints and concerns for schools which are more comfortable for both parents and children to operate in. As Claire Alexander argues:

'choice' for BME families is not straightforwardly allied to notions of individual educational achievement or aspiration, but to an intersection of factors. These include structural barriers to accessing necessary information, institutional constraints on the kinds and quality of schools available to those families living in deprived areas, the demand for ethnic, gender or religion-specific provision and less tangible considerations around location, safety and reputation. (in WeekesBernard 2007: piii)

Quantitative research does suggest that racialised choices are being played out in schooling. In a study on schools in England, Johnston et al. found that: ' $[\mathrm{b}] \mathrm{oth}$ whites and non-whites are more concentrated into schools with their co-ethnics than predicted by a random allocation model' (Johnston et al. 2004: 246). In this study, they found evidence of higher levels of segregation in schools than in residence. In areas that were more ethnically mixed, they found a greater concentration of both whites and non-whites (this was particularly the case with Asian populations) (see also Burgess et al. 2005 for similar findings). 


\section{All in the mix}

Thus, the choice ambitions and practices of those with fewer economic, social and cultural resources can often be overlooked and their engagement in processes of choice ignored. For Reay and Ball (I997: 93):

Working class patterns of educational choice are characterised by ambivalence, and appear to be as much about the avoidance of anxiety, failure and rejection as they are about 'choosing a good school for my child'.

The selection of and attendance at school involves a series of dispositions and practices which draw on different classed capitals. Economic resources play an important role. This occurs at the mundane level of ability to visit schools that are further from home and also to contemplate sending a child to a more distant school, which may involve transport costs or require having the time and the car to drive children to school. But economic resources may also work at the level of moving house in order to fall into the catchment area of a 'better' school. Or indeed, as we shall see in Chapter 2, people may move to a particular area before having children because it has enough 'people like us' and then realise, less than coincidentally, that they also like the nearby schooling. Cultural and social resources are also important in giving parents the ability to access and assess the 'hot' and 'cold' information on schools - from appraising Ofsted reports to using networks to evaluate schools. There is evidence that different classes tend to use different sources for this and, as we argued in Byrne and De Tona 20I2, there are particular challenges faced by migrants who did not have their own education in Britain. The middle classes may well have a better 'sense de jeu' which enables them to get the most out of the education system. For example they recognise the importance of 'traditional' subjects which fit in to current 'hierarchies of knowledge' and help to secure access to the more prestigious universities (Francis et al. 20I7; Toth, et al. 20I5). ${ }^{15}$

Diane Reay (I999), looking at the experiences of both working-class and middle-class mothers, argues that middle-class parents are much more confident in dealing with the education system in general. This is likely to translate into confidence in negotiating the possibilities of choice. The middle classes may make more vigorous and successful use of the appeals system, and researchers have found that middleclass parents are quick to argue that their child is specifically gifted and/or needs special assistance and treatment which may assist their 


\section{Unequal choosing}

position in the appeal process (Ball 2003: 62, Devine 2004: 222). In the transition from primary to secondary schools, the middle classes may also be better at enlisting teachers' and other support, including private tuition where entry to grammar schools is based on exams which primary schools do not equip children for.

As we shall argue in this book, race and class are interwoven in the ways they shape the fears, anxieties, aspirations and desires and the social practices that are produced as a result of them. Thus the literature on school choice has frequently ignored the extent to which class and race should be understood as mutually constituted, even in those cases where issues of race do not seem to be present, because the research participants are all white (Byrne 2006b, 20I5). An important exception to this tendency to overlook productions of whiteness is Diane Reay and her colleagues who have explicitly examined the experiences of white middle-class parents in choosing 'mixed' innercity schools 'against the grain' of what might be suggested as general middle-class choices. For some, they argue, these choices serve to display their liberal credentials and secure their class position: mixed schools can offer a form of 'multicultural capital' (Reay 2008, Reay et al. 20II). In addition, more studies have now explored ethnic-minority processes of school choice. However, this has also tended to explore the experiences of middle-class respondents (Weekes-Bernard 2007, Francis and Archer 2005, Archer 20I0, 20II, Vincent et al. 20I2, Ball et al. 20II). Yet ethnic minorities may bring particular concerns to the question of school choice which interact with class in different ways. Some have highlighted how ethnic-minority middle classes share many of the parenting practices and strategies of the white middleclass counterparts (Lareau and McNamara Horvat I999, Archer 20I0, Ball, et al. 2002). However, there are complex racialised elements that set their experiences apart from those of the white majority. This may include concerns about their children facing racism in schools (as we shall see in Chapter 5), but may also relate to their ease as parents in interacting with school structures. For example, there is evidence that schools are more accepting of white parents' assertiveness than that of minority-ethnic parents, who also feel more ambivalent and reflexive and ultimately less confident in adopting the 'complaining parent persona' (Archer 20I0: 465, see also Ball et al. 20II). For racialised minorities, even those with economic and cultural capital, this may not translate easily into the ability to achieve the outcomes they want. Debbie Weekes-Bernard argues that: 


\section{All in the mix}

the current education market and its promotion of increased parental choice may require parents from some BME communities to engage in processes of 'flight', which may result in their children being educated in schools, and their families living in residential areas, where they form a clear minority. (Weekes-Bernard 2007)

Such flight then has potential social and cultural implications and the same parents were often worried about their children suffering increased racism as a result. This racism may include hostility and stereotyping from other children, but also from teachers and the school structures (Gillborn et al. 20I2, Archer 20II, Vincent et al. 20I2).

Nonetheless, as argued above, the greater part of the literature on parents choosing schools is focused on white middle-class parents and often fails to explicitly consider their racialised positions. At the same time, there has been growing concern about the achievement (rather than the choosing) of white working-class children - and particularly boys - in UK schools (Gillborn 2009). David Gillborn has critiqued the way that this concern for the 'white working class' tends to focus attention on questions of ethnicity (for example, looking at the differences in achievement between white boys on FSM and black African boys on FSM rather than class (the differences between the achievement of white FSM and non-FSM boys). Thus the slightly better achievement of African FSM boys serves to distract from the larger inequalities within the white group, where the white non-FSM boys are hugely overachieving compared to the white FSM boys (Gillborn 2009). In a popular discourse where the 'white working class' - or what are sometimes called the 'left behind' - are seen as a source of support for right-wing parties (depending on the era, of BNP, EDL; and, in the context of Brexit, UKIP and leave supporters), these constructions of the 'problem' of the white working class can mean that 'politicians and commentators invoke the threat of racist violence as a means of disciplining calls for greater race equality' (Gillborn 2009). In addition, as for the most part the only social statistics collected on school children are whether they are in receipt or not of free school means, the conflation of FSM and working class serves to obscure diversity of outcomes and experiences within the working classes - which includes denying the class status of ethnic minorities (Bottero 2009).

The following section will explore how school choice depends on certain spatial practices and relationships. This is a commonly overlooked factor in research on school choice, despite the importance of 


\section{Unequal choosing}

geography in decisions around schools which includes the role place plays in consideration of reputation of desirable and undesirable schools.

\section{Choices and relations as spatialised}

The question of place and spatial location has been an underdeveloped area in reference to much of the writing on school choice. ${ }^{16}$ Even for those schools which do not have distance from school as a criterion for residence, practical questions of getting children to and from schools dictate limitations as to which school they can apply to. This means that there are important interrelations between schools and local areas, and that parents negotiate school choice spatially. This spatial relationship is not confined to simply thinking of the schools that are near enough or convenient; also, as shall be discussed in Chapter 2, schools are understood at least partially through the reputation of area - and vice versa. A 'bad' school can play an important role in the stigmatisation of an area and can be the means through which both race and class are narrated in particular spaces. In addition, the potential for children to feel a sense of belonging in the school will be influenced by a more general sense of belonging in the area. While Bourdieu does not see the 'field' as a geographic space, it nonetheless has spacialised dynamics. Following De Certeau, we would suggest that places are made and claimed through engagements with wider social processes and societal structures. They are relational - the result of relations between people and between objects and people. Places are also storied - in that they are lived in and told through stories (De Certeau I984). We argue that schools can play an important role in shaping the narratives of particular places. Nonetheless, the spatial boundaries of a school community constructed by catchment areas may contrast with the 'tactics' of those who live in the surrounding areas and walk their cities through unofficial routes, daily encounters and shortcuts (De Certeau I984). Places and the interactions which take place in them provide one structure through which stories of the self, of community and belonging, of change and history, are told. Stories of place, particularly urban places, are temporal - telling of economic and population change, of people coming together, moving in and moving away. As Harvey points out, there is an 'intimate connection' between the 'development of capitalism and urbanisation' (Harvey 2008). 


\section{All in the mix}

Places are the setting of work and home-making and of politics, consumption and leisure as well as the setting for schooling. Inevitably, they are deeply gendered, classed and raced (Massey I994, Neely and Samura 20II). Stories about place are an integral part of race-making (Knowles 2003). For Harvey, the urban dweller is defensive, territorial and competitive about their urban space, creating spatial barriers or 'bounded space' (Reay et al. 20ıг: 56). Places, and stories about place, are relational and can tell us about who is constructed as an outsider and who has taken the place of the 'native' with claims to place as 'home'. Stories also carry valuations of place, with modes of narrating stigmatisation, degeneration, regeneration or gentrification. With migration, be that regional, national or international as the basis of producing the urban, these narratives have racial and cultural difference woven through them. Accounts of place are bound up in the elusive notion of reputation and the ways in which places are shaped by geographies of fear, neglect, pride, aspiration, nostalgia and trust, tied up in the production of affect (Thrift 2004). Space is a social product - produced through the relations of things and social relations within multiple temporalities For De Certeau 'haunted places are the only spaces people can live in' (De Certeau I984) while for Lefebvre: 'The past leaves its traces; time has its own script. Yet this space is always now and formerly, a present space, given as an immediate whole, complete with its associations and connections' (Lefebvre I991: 37). Places are not necessarily clearly defined, but shifting with porous boundaries. As will be shown in Chapter 2, people relate differently to schools which they have perhaps attended themselves or at least known of for a long time. These are indeed 'haunted places' with pasts that are not forgotten just through a change in the name of the school (a common move in attempts to 'rebrand' schools which have had poor reputations). We will see some of this 'haunting' where parents who have grown up locally still read schools through the reputation and their experiences of them in their childhoods, rather than relying on the current accounts told by the schools or Ofsted reports. ${ }^{17}$ In addition, the intake of a school can be one means through which a place comes to be understood as having a particular spatial parameter; as we shall see in Chapter 2, it interrelates with a wider narrative of place and community. Schools play an important role in gentrification, with white middle-class parents sometimes hoping for a critical mass of 'people like us' to turn a school around (Ball 2003, Reay et al. 20II). 


\section{Unequal choosing}

This may mean at times that the older-established white and nonwhite working class become priced out of an area.

Places, like schools, are heavy bearers of reputation where class and race can both work to mark places as somehow failed - thought of as problem places and problem people through what Paton et al. 2016 describe as 'territorial stigmatization'. This occurs in what Lefebvre calls 'representational space' - the space of the imagination which is produced through symbolic images rooted 'in the history of people as well as in the history of each individual belonging to that people' (Lefebvre I99I: 4I). Representational space is to be distinguished from the 'representations of space', the more official abstract mode of representing space which, in the context of education, is conceived by government and local planners as well as by school heads and admissions committees. But Lefebvre is also interested in spatial practices - the everyday interactions and the site of daily routines and the everyday ways of moving through the city for work, home and pleasure. Different spaces produce different modes of performance and competence to participate in: what Bourdieu might characterise as dispositions - or what Lefebvre calls 'spatial codes':

a means of living in that space, of understanding it and producing it. As such it bring together verbal signs (words and sentences), along with the meaning invested in them by a signifying process) and nonverbal signs (music, sounds, evocations, architectural constructions). (Lefebvre 1991: 48-9)

This is perhaps particularly true of the intensely social and also disciplined space of a school. The act of choosing schools requires relating to and deliberating on the implications of all these conceptualisations of space - from everyday practices, to official renditions, to emotionally overlaid questions of reputation - all of which, as we shall see in the following chapters, are also raced, classed and gendered. For parents, these acts of choosing are happening at a time when often they feel that their children are particularly vulnerable to the pressures to modify themselves to fit in. Thus, in thinking about schools as places of intense interaction and formation of the self, this question of representational space, with modes of stigmatisation and valorisation can potentially have a deep impact. Just as there can be territorial stigmatisation, places can also be remade through processes of gentrification. Savage et al. (2005) argue that particular sections of the middle class ('liberal metropolitan' - as opposed to the 


\section{All in the mix}

'corporate' or 'postmodern') embrace, and create, a sense of belonging in areas that they are attracted to because of their diverse and colourful nature. For Savage et al, these middle classes claim a sense of belonging - 'elective belonging' - through having made the decision to move into the area rather than narratives of having come from areas. Butler and Hamnett, examining the interplay between gentrification and education, argued that 'Non middle-class households do not have the necessary resources to devise and execute the complex strategies adopted by middle-class households for their children's education' (Butler and Hamnett 20II: 7).

As mentioned above, schools are often engaged in forms of branding in order to attract the 'best' children and parents. Courtney defines branding as 'any appellation or status representing or invoking a characteristic, or set of characteristics, which may be claimed by or attributed to a school to associate with other schools possessing the same status, and which is consequential in an education market' (Courtney 20I5: 8I3). This may take the relatively low-level form of a school advertising its results, but is also built on renewal of school buildings (the New Labour government in particular had a large programme of improving school buildings) and promotion of new uniforms with implied disciplinary codes that often go alongside school uniforms. Reputation is also developed in reference to 'competitor schools' in the same 'circuits of schooling' (Ball et al. 1995). As we shall see in Chapter 3, these visual markers of schools do make an impression on both parents and children. At the same time, the reputation or brand of the school can also serve to mark the children who attend it and, by extension, their parents as either stigmatised or with social status. As Reay et al. note (20II: 2I), '[s]chooling is, then, a high-stake business in the formation of identities'. These brands and identities can be part of a complex interplay between the school itself, its reputation and intake and the reputation and intake of the surrounding area.

\section{Conclusion}

This chapter has set out both the location of this book within the literature and the gaps that it seeks to address. Questions of class, race, gender and inequality have long been central to research on schooling and have played an important role in the rise and fall and rise again of class analysis within sociology. The field of educational research has been particularly central to an approach to class which is influenced 


\section{Unequal choosing}

by the works of Bourdieu. However the chapter has outlined the ways in which the intersecting nature of class and race has been overlooked in research on school choice, including work influenced by Bourdieu. There is a tendency to focus on middle-class experiences and aspirations. The same would hold for gender and religion - which will be explored in later chapters. The chapter argues that, if we are fully to understand parents' accounts of choosing schools, we need to track how discourses of both race and class contribute to their understanding of desirable - or undesirable - schools. It is important to ask whether and how parents' talk about school choice is performative of race as well as class. In the literature on school choice, these questions are more often asked of parents who don't have racialised or classed privileges, although racialised and classed considerations are also likely to be as important in understanding the practices and motivations of the privileged. The chapter has also explored how choosing schools is spatialised, dependent as it is on certain geographical rigidities of practical and financial limitations. As the next chapter will explore in more detail, schools have an intimate relationship to the areas in which they are sited. Schools' reputations are dependent on the areas in which they lie, as location largely determines who attends the school. At the same time, changing representations of schools can alter the ways in which not only schools but also areas are understood.

\section{Notes}

I Lupton (20II), following Barker (20I0) prefers the term 'school markets and competition' to refer to the 'systems for organising school provision in which educational providers (schools) produce educational commodities (curriculum, teaching, facilities, ethos and so on) and compete with each other to "'sell'" them to consumers (parents, pupils)' (Lupton 20II: 3IO-3II). However, we will continue to use 'school choice' as a short-hand for describing that process - as we are focused on the specific process of parental choice.

2 www.theguardian.com/teacher-network/2016/may/04/parent-governors -schools-battle-engage-families, accessed i6 January 2017.

3 In December 20I6, fewer than I per cent of state-school-educated pupils went to free schools (Parliamentary statistics on free schools: file://C:/ Users/msrssbb3/Downloads/SNo7033\%20(I).pdf, p. 4).

4 www.gov.uk/government/publications/open-academies-and-academy-pr ojects-in-development, accessed 24 February 2017. 


\section{All in the mix}

5 www.tes.com/news/school-news/breaking-news/government-scraps-edu cation-all-bill, accessed 24 February 2017.

6 In term of governance, as a result of increased academisation, there is less direct oversight of schools by local authorities or other elected institutions - placing even more importance on market-based accountability for raising standards in schools.

7 See Bottero (2004) for a critique on this extension of class to the cultural.

8 Although there has also been a recognition of a broadening of classed practices by the middle classes which resignify formerly working-class practices (such as supporting football or liking popular music), which consumed in a similar way to classical music or cricket can be understood as a cultured omnivorous and middle-class practice. These examples alert us to the importance of considering how class is a question not just of what tastes you have but also, importantly, how you display those tastes.

9 See also Reay (2004) for a discussion of the misuse of habitus within educational research.

IO See Puwar 2009, Go 2013 and Loyal 2009 for a discussion of Bourdieu's reading of race, particularly in the context of Algeria.

II Although see Hage (I998) for an interesting take examining the cultural and symbolic capital wrapped up in racialised ideas of the nation and national belonging.

I2 Generally, statistics on income or class background is not collected in schools. However, 'free school meal' provision, which is an incomerelated benefit, is often used as an indicator of deprivation (although it relies on parents applying for the benefit and does not capture the deprivation of some immigrants who, depending on their residency status, are not eligible for FSM). See Gillborn et al. (2OI2) and Gorard (20I2) for further discussion.

I3 Although Reay et al. in contrast focus on 'against the grain' choosers who are prepared to 'risk' sending their children to inner-city multi-ethnic schools.

I4 This is a familiar characteristic of whiteness and white privilege which is protected by the ways in which it is ignored, silenced or unexamined; see Byrne (2006b).

I5 The Russell Group universities recognise this advantage and are trying to counter this uneven knowledge by being transparent about what they see as 'facilitating subjects'.

I6 See Kerr et al. (20I4) for a discussion of the importance of understanding the role of place and neighbourhood in educational outcomes.

I7 Ofsted, or the Office for Standards in Education, Children's Services and Skills, is a government body, established in I992, that inspects and regulates schools in England (and other services providing care and education to children). Every school in England is regularly inspected by Ofsted, 


\section{Unequal choosing}

which publishes a public report (available online) on the results of the inspection. Schools are graded from 'outstanding' to 'inadequate' and Ofsted has the power to place schools into 'special measures' if it judges schools to be inadequate. 